\title{
Rituales de terminación y consumo en el Palacio 6J2 de La Blanca: una perspectiva zooarqueológica del Clásico Terminal en el Petén guatemalteco
}

\section{Termination and Consumption Rituals in the 6J2 Palace of La Blanca: A Zooarchaeological Perspective of the Terminal Classic in the Guatemalan Peten}

\author{
NAYeli G. JimÉnez CANO \\ Universidad Autónoma de Yucatán, México \\ Cristina Vidal Lorenzo \\ Universidad de Valencia, España
}

\begin{abstract}
Resumen: La Blanca es un asentamiento urbano localizado en el Petén guatemalteco, que jugó un papel importante en la antiguiedad debido a su ubicación estratégica en la cuenca del río Mopán. En este trabajo se presentan los resultados de los estudios zooarqueológicos de un conjunto de materiales correspondientes al periodo Clásico Terminal (850-1000 d.C), una época socialmente convulsa y en la que la élite de La Blanca abandonó la ciudad y nuevos moradores ocuparon las estancias palaciegas. La fauna estudiada procede de la excavación del ala sur del Palacio 6J2 de la Acrópolis y representa una oportunidad única para identificar el uso ritual de la fauna en un periodo de crisis social y económica. Asimismo, los vestigios analizados ponen de manifiesto la importancia de los ambientes cercanos para la obtención de recursos destinados a la subsistencia, al tiempo que representan un primer acercamiento para aportar claves sobre la importancia económica de las especies aprovechadas y el papel que jugaron los animales en las actividades rituales durante un periodo tan discutido en la historia maya como lo es el Clásico Terminal en las Tierras Bajas.

Palabras clave: zooarqueología; ritual; aprovechamiento; Clásico Terminal; La Blanca.
\end{abstract}

ABSTRACT: La Blanca is an urban settlement located in the department of Petén, Guatemala. The site played an important role due to its strategic location alongside 
the Mopán River basin. This paper presents results of the zooarchaeological studies conducted on this archaeological site during the Classic Terminal period (850-1000 A.D.), a time of social upheaval in which the elite of La Blanca left the city and new inhabitants occupied the rooms of its monumental palaces. The animal remains analyzed came from the excavation of the south wing of Palace $6 \mathrm{~J} 2$ at the Acropolis and represent a unique opportunity to understand the faunal use and management in a period of social and economic crisis. The animals deposited in these rooms pointed to the ritual character of the assemblage as well as the importance of the nearby environment as a means of providing resources for subsistence. The study of the archaeofaunal assemblages represents a first approach to provide clues about the economic importance of the animals and their role in ritual activities during a so debated period in Maya history as the Terminal Classic in the Lowlands.

KeYwords: zooarchaeology; ritual; exploitation; Terminal Classic; La Blanca.

ReCEPCIón: 20 de febrero de 2020.

ACEPTACIÓN: 30 de abril de 2020.

DoI: https://doi.org/10.19130/iifl.ecm.57.2021.18654

\section{Introducción}

Las relaciones hombre-medioambiente en el área maya durante la época prehispánica eran variadas y se extendían más allá de su aprovechamiento para la obtención de recursos de subsistencia. En este sentido, los animales eran utilizados, además, como materia prima para la fabricación de artefactos y algunos de ellos cumplían una importante función simbólica en los rituales u ofrendas. Todas estas relaciones constituyen un interesante tema de estudio en tanto que son reflejo de la manifestación de comportamientos sociales cuyos caracteres formales permiten que sean analizados e interpretados arqueológicamente.

En este trabajo se exponen los resultados de los análisis zooarqueológicos de la fauna recuperada en la excavación del ala sur del Palacio 6J2 de la Acrópolis del sitio arqueológico La Blanca, concretamente del Cuarto 4 y del exterior del Cuarto 3. Este asentamiento urbano maya se encuentra localizado en el departamento de Petén, Guatemala, en la cuenca del río Mopán, a aproximadamente $2 \mathrm{~km}$ de distancia de la aldea que lleva el mismo nombre (Figura 1). El sitio se extiende en un extenso valle, inundable en época de lluvias y, en la actualidad, muy deforestado. Sin embargo, en la antiguiedad todo este territorio estaba ocupado por el denso bosque tropical. En este entorno natural los mayas no sólo encontraron una extraordinaria abundancia de especies vegetales necesarias para la construcción y la fabricación de herramientas y otros utensilios domésticos, sino también numerosos animales, fundamentales tanto para su dieta como para el desarrollo de otras actividades de carácter ritual, como más adelante demostraremos. 


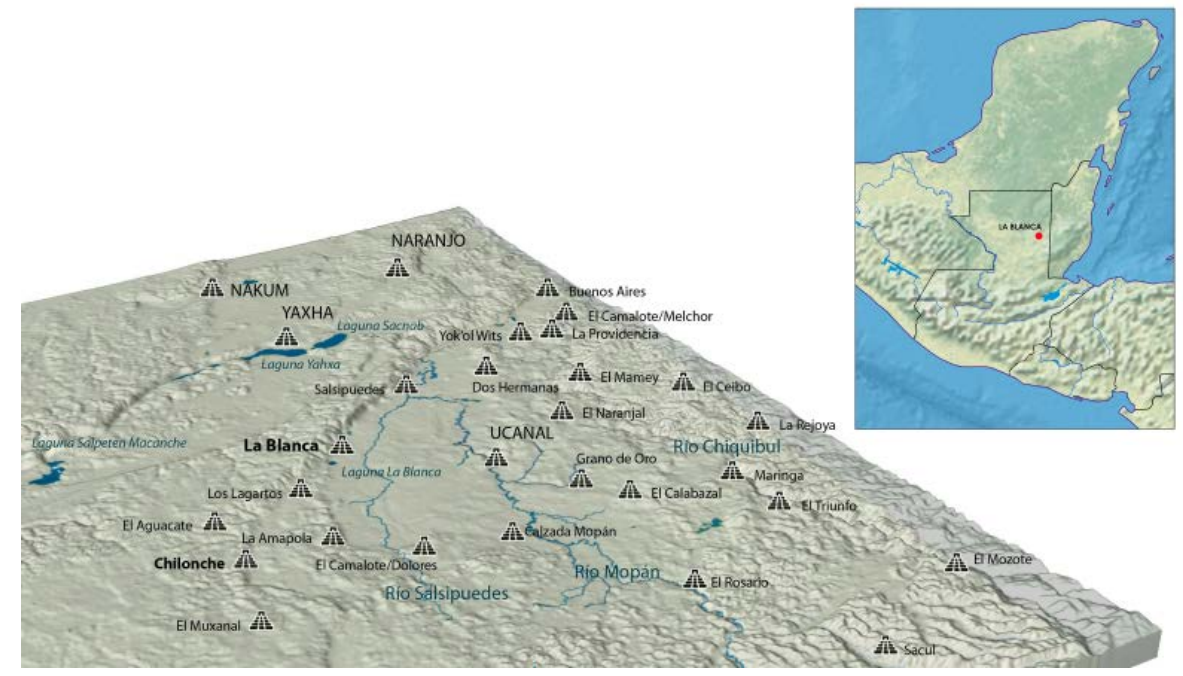

Figura 1. Mapa de la cuenca del río Mopán con indicación de los principales sitios arqueológicos de la región, entre ellos La Blanca (Proyecto La Blanca, 2012).

Dentro del valle del Mopán, La Blanca se enmarca en la subcuenca del río Salsipuedes, a la que pertenecen otras entidades políticas, entre las que destacan Chilonché, El Muxanal, La Amapola, El Aguacate y Los Lagartos. Durante el Clásico Terminal los asentamientos de esta región tuvieron que hacer frente a la profunda crisis que asoló al área maya. Una crisis que no sólo afectó a las élites que habitaban en las grandes capitales, sino también a los centros de menor tamaño como La Blanca, cuya privilegiada localización cercana a los ríos se vio profundamente afectada debido a los desequilibrios ocurridos en el comercio, lo que provocó cambios económicos y sociales relevantes (Laporte, 2004: 229; Muñoz y Vidal, 2014: 42; Vidal y Valdés, 2007: 19). Como consecuencia de todo ello, La Blanca fue abandonada por las élites que la habitaron al final del periodo Clásico. Es muy probable que este abandono se haya realizado de una manera organizada, ya que no se encontraron evidencias de un abandono súbito y precipitado. Ahora bien, cuando se produjo el abandono, varios de los edificios se encontraban en plena renovación, de modo que dichas obras nunca llegaron a concluirse, tal como ha podido demostrarse durante su excavación por parte del Proyecto La Blanca (Vidal y Muñoz, 2013: 100; 2016a: 66; 2016b: 101). Más adelante, el sitio siguió siendo visitado por otros moradores, los cuales llevaron a cabo diversas actividades en los edificios ya semiderruidos que en otro tiempo pertenecieron a las clases más privilegiadas, pero sin ocuparse de su mantenimiento y conservación, entre ellos el Palacio 6J2 (Valdés y Vidal, 2007: 179). Allí enterraron a sus muertos, al tiempo que otros entierros de época anterior fueron revisitados y 
perturbados. Prácticas similares tuvieron lugar en el Posclásico Temprano, si bien para entonces los niveles de derrumbe de este excepcional palacio llegaban en la mayoría de sus cuartos hasta el arranque de la bóveda (Vidal y Muñoz, 2016b: 104; Vidal y Horcajada, 2020: 114).

El Palacio 6J2 fue erigido en la cima de la monumental Acrópolis de La Blanca (Figura 2). Tiene forma de "C" y posee 18 espaciosos cuartos con bóvedas de elevada altura y anchos vanos. En todos hay amplias banquetas longitudinales, excepto en los centrales de cada sector (norte, oeste y sur), cuyas banquetas están en los laterales, a ambos lados de cada cuarto, ya que éstos actúan como paso entre el exterior del palacio y el gran patio interior de la Acrópolis.

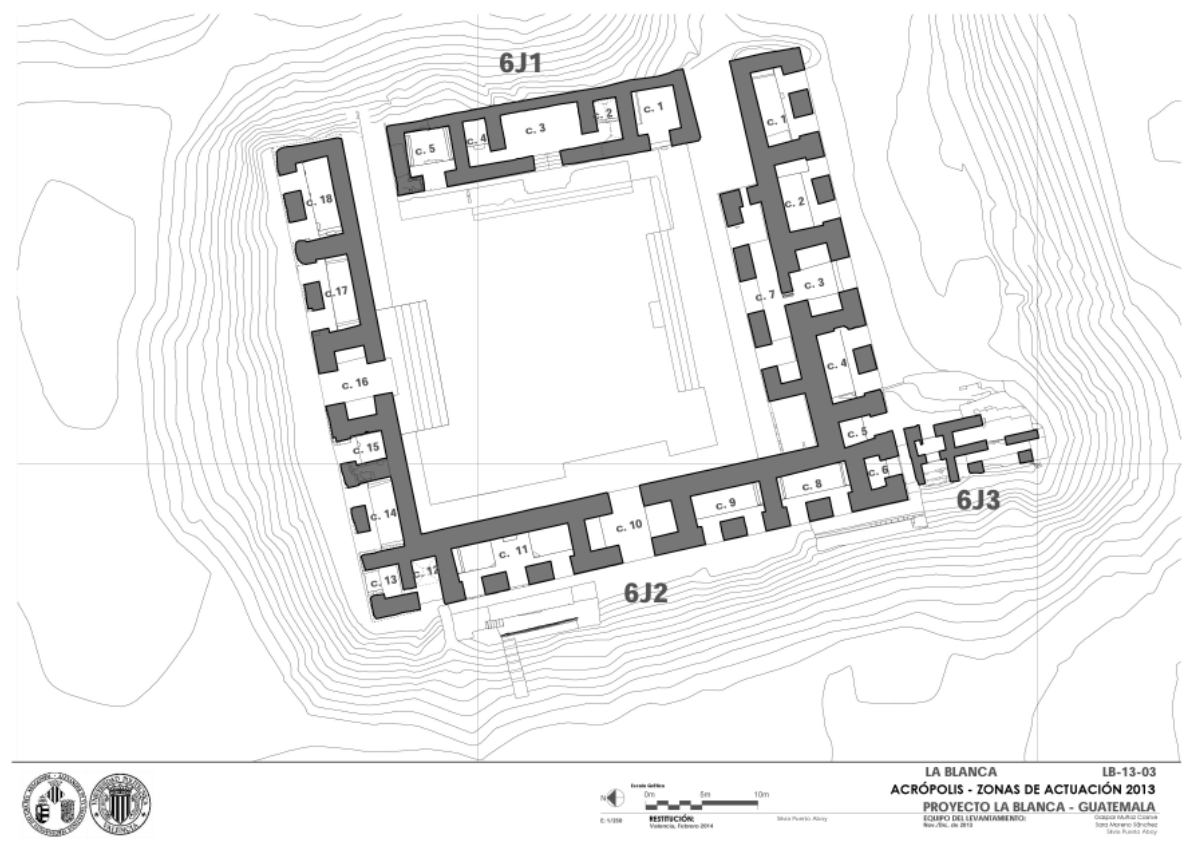

Figura 2. Plano de la Acrópolis de La Blanca con indicación de los Palacios 6J1, 6J2, 6J3 y sus cuartos (Proyecto La Blanca, 2013).

Los Cuartos 3 y 4 pertenecen al ala sur de $6 \mathrm{~J} 2$, y fueron los primeros que se excavaron por parte del proyecto La Blanca (Figura 3). El Cuarto 4 es conocido como Cuarto de los Grafitos, ya que en sus muros abundan estas singulares manifestaciones artísticas de la cultura maya, muchos de los cuales representan animales. El Cuarto 3 es el cuarto de paso entre el lado sur del palacio y el Cuarto 7 , cuya fachada se abre al patio central. En sus muros también hay interesantes grafitos, destacando entre ellos las representaciones arquitectónicas. 


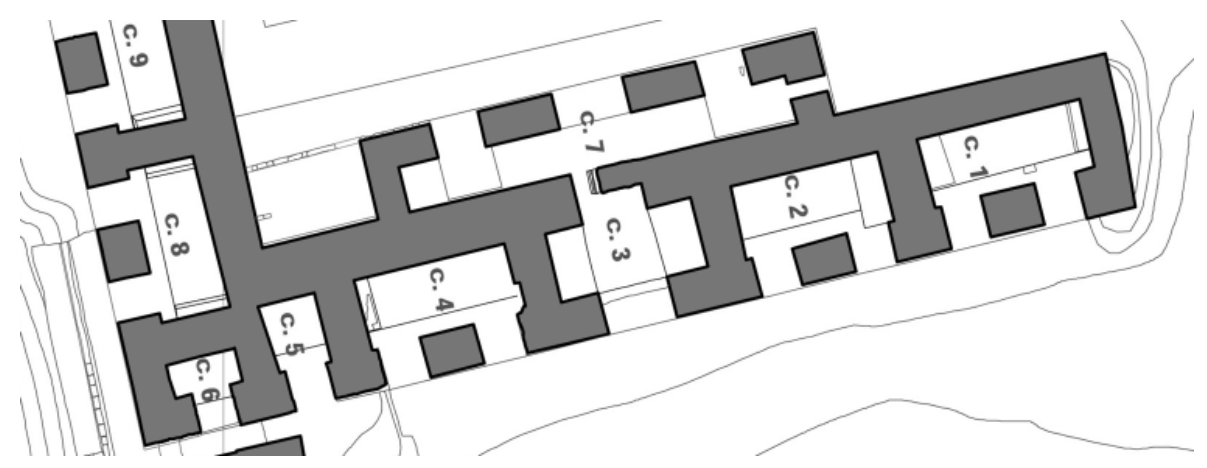

Figura 3. Detalle de la planta del ala sur del Palacio 6J2 con indicación de sus cuartos (Proyecto La Blanca, 2014).

Los materiales arqueológicos objeto de este estudio fueron encontrados durante la excavación de los cuartos del palacio e interpretados como ofrendas o rituales llevados a cabo en el interior y exterior de dichos espacios con motivo del cese de actividad en los mismos, coincidiendo con el abandono del sitio por parte de sus habitantes, a finales del Clásico (Vidal, 2006: 23; Vidal y Muñoz, 2009: 146; 2017: 238). No obstante, y como ya hemos apuntado, dado que en este sector de la Acrópolis también se produjo una ocupación en el periodo Posclásico Temprano, la adscripción cronológica de los restos faunísticos, especialmente los del Cuarto 4, presentó ciertas dificultades al no estar asociados a materiales diagnósticos exclusivos de uno de esos periodos (Vidal, 2006: 14).

Partiendo de tales premisas, el objetivo principal del presente trabajo es identificar si efectivamente los conjuntos arqueofaunísticos de este sector del Palacio 6J2 corresponden a la realización de actividades rituales durante el Clásico Terminal y, si lo fueran, determinar qué elementos faunísticos fueron reservados para este fin y de qué manera fueron llevadas a cabo estas actividades. Además, se busca profundizar en el conocimiento del aprovechamiento faunístico durante un periodo de inestabilidad social en La Blanca y su entorno, así como la identificación de los animales que pudieron ser reflejo de las actividades de consumo humano en periodos más tardíos.

\section{Materiales y métodos}

El Proyecto arqueológico La Blanca tenía entre sus objetivos de investigación el estudio de la fauna arqueológica, de ahí que se haya puesto especial cuidado en la recuperación de los restos faunísticos hallados en las excavaciones de las distintas estructuras a lo largo de las quince temporadas de campo en que se ha desarrollado el proyecto, sin menospreciar aquellos procedentes de los niveles 
de derrumbe o de los estratos más superficiales, los cuales fueron exhumados en forma minuciosa. El conjunto zooarqueológico objeto de esta contribución procede de la campaña de excavaciones del año 2005 (Muñoz y Vidal, 2006), las cuales se concentraron, sobre todo, en el ala sur del Palacio 6J2 (Figura 4). Como método de extracción y examen durante la recolección de los restos faunísticos en campo se procedió al tamizado en seco de toda la muestra, utilizando para ello cribas de $1 \mathrm{~mm}$ con el fin de asegurar la recuperación de todos los vestigios, incluidos los de la microfauna.

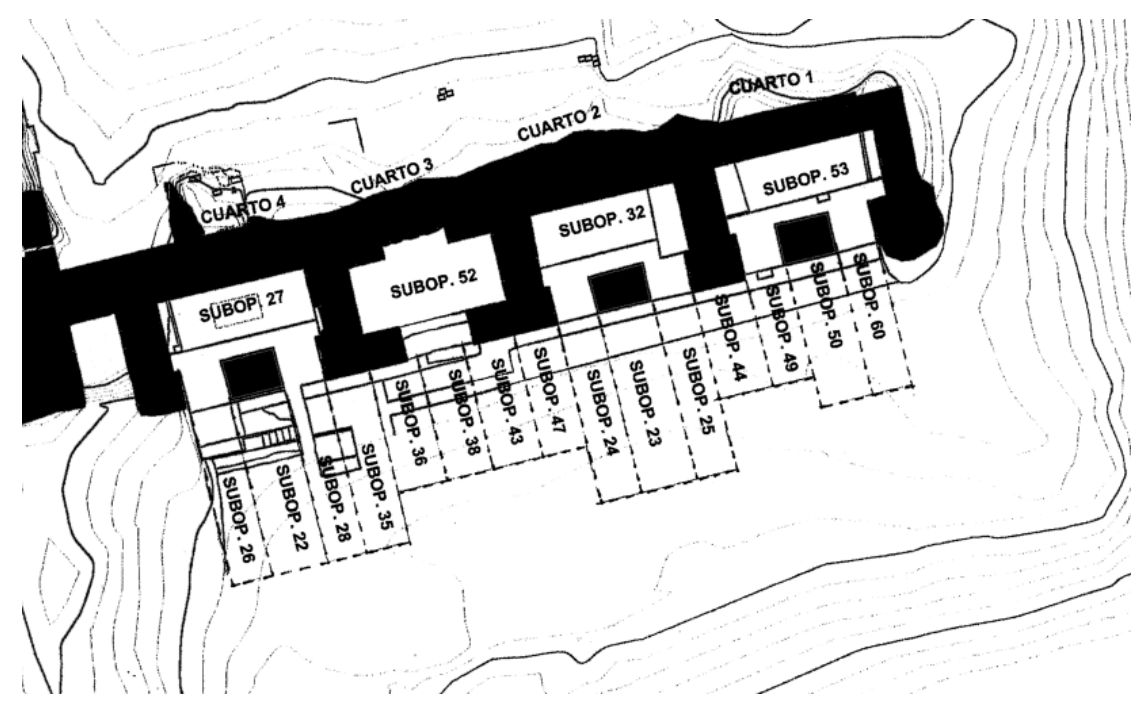

Figura 4. Planta del ala Sur del Palacio 6J2, con indicación de las suboperaciones realizadas en la temporada de campo 2005 (Proyecto La Blanca, 2005).

Los análisis realizados en laboratorio (Jiménez, 2016; 2017) incluyeron la identificación anatómica y taxonómica de los restos osteológicos de la fauna, para lo cual se utilizó la colección osteológica de referencia faunística de Arturo Morales, alojada en el Laboratorio de Arqueozoología (LAz) de la Universidad Autónoma de Madrid. Además, y a modo de apoyo bibliográfico se han consultado obras como las de Olsen (1968; 1982) y Morales, Arroyo y Polaco (2010). Los restos que no presentaron criterios específicos para su identificación, o cuando la colección comparativa no contaba con los especímenes afines, se agruparon en la categoría de indeterminados (indet.). Las marcas tafonómicas también se han registrado, indicándose entre ellas las marcas de afectación térmica, de corte o marcas de roído.

Los estimadores de abundancia utilizados en este estudio han sido el número de especímenes identificados (NISP) y el número mínimo de individuos (MNI). Para llevar a cabo el cálculo del MNı se siguieron los criterios de Clason (1972) en donde se separan los huesos de acuerdo con la parasagitalidad, y se obtiene el MNI del lado del mayor número de piezas. 


\section{Resultados generales}

El conjunto arqueofaunístico estuvo compuesto por un total de 430 restos, comprendiendo 38 individuos. A pesar de tratarse de una muestra pequeña, la fauna de estos conjuntos resultó muy diversa tal como puede observarse en la Tabla 1.

\begin{tabular}{|c|c|c|c|c|c|c|c|}
\hline \multirow{2}{*}{ TAXON } & \multirow{2}{*}{ NOMBRE COMÚN } & \multicolumn{2}{|c|}{ CUARTO 3} & \multicolumn{2}{|c|}{ CUARTO 4} & \multicolumn{2}{|c|}{ TOTAL } \\
\hline & & NISP & MNI & NISP & MNI & NISP & MNI \\
\hline Ictalurus furcatus & bagre de agua dulce & & & 2 & 2 & 2 & 2 \\
\hline Petenia splendida & tenguayaca, blanco & & & 1 & 1 & 1 & 1 \\
\hline Cichlidae cf. Cichlasoma & mojarras & & & 2 & 1 & 2 & 1 \\
\hline Cichlidae indet. & mojarras & & & 1 & 1 & 1 & 1 \\
\hline $\begin{array}{l}\text { Testudines cf. Chelydra } \\
\text { rossignonii }\end{array}$ & tortuga lagarto & 1 & 1 & & & 1 & 1 \\
\hline Dermatemys mawii & tortuga blanca & & & 6 & 1 & 6 & 1 \\
\hline Kinosternidae indet. & tortugas de pantano & & & 28 & - & 28 & 0 \\
\hline Rhynochlemmys sp. & $\begin{array}{l}\text { tortuga madera } \\
\text { mexicana }\end{array}$ & & & 6 & 1 & 6 & 1 \\
\hline Testudines indet. & tortugas sin identificar & 8 & - & & & 8 & - \\
\hline Meleagris $\mathrm{sp}$ & pavos & & & 7 & 1 & 7 & 1 \\
\hline Aves indet. & aves sin identificar & 1 & 1 & 50 & - & 51 & 1 \\
\hline Didelphis sp. & zarigüeyas & & & 6 & 2 & 6 & 2 \\
\hline Dasypus novemcinctus & $\begin{array}{l}\text { armadillo de nueve } \\
\text { bandas }\end{array}$ & & & 8 & 1 & 8 & 1 \\
\hline Cricetidae indet. & ratas y ratones & & & 3 & - & 3 & 0 \\
\hline $\begin{array}{l}\text { Geomydae cf. } \\
\text { Orthogeomys }\end{array}$ & tuzas & & & 4 & 1 & 4 & 1 \\
\hline Erenthizontidae indet. & puercoespines & & & 1 & 1 & 1 & 1 \\
\hline Cuniculus paca & tepezcuintle & & & 50 & 3 & 50 & 3 \\
\hline $\begin{array}{l}\text { Cavoidea cf. C. paca ID. } \\
\text { punctata }\end{array}$ & tepezcuintle o agutí & & & 1 & 1 & 1 & 1 \\
\hline $\begin{array}{l}\text { Procyonidae cf. Nasua } \\
\text { narica }\end{array}$ & $\begin{array}{l}\text { pizote/ coatí de nariz } \\
\text { blanca }\end{array}$ & & & 1 & 1 & 1 & 1 \\
\hline Canis lupus familiaris & perro doméstico & 1 & 1 & & & 1 & 1 \\
\hline Puma concolor & puma & & & 3 & 1 & 3 & 1 \\
\hline Odocoileus virginianus & venado cola blanca & 14 & 3 & 10 & 2 & 24 & 5 \\
\hline Mazama sp. & venado temazate & 5 & 2 & 1 & 1 & 6 & 3 \\
\hline Cervidae indet. & venados & 5 & - & 9 & - & 14 & 0 \\
\hline $\begin{array}{l}\text { Tayassuidae cf. Tayassu } \\
\text { pecari }\end{array}$ & $\begin{array}{l}\text { pecarí de labios } \\
\text { blancos }\end{array}$ & & & 5 & 2 & 5 & 2 \\
\hline Tayassu pecari & $\begin{array}{l}\text { pecarí de labios } \\
\text { blancos }\end{array}$ & 4 & 3 & 1 & 1 & 5 & 4 \\
\hline Tayassuideae indet. & pecaríes & & & 19 & - & 19 & 0 \\
\hline Tapirus bairdii & tapir & & & 11 & 2 & 11 & 2 \\
\hline Mamífero indet. & $\begin{array}{l}\text { mamíferos sin } \\
\text { identitificar }\end{array}$ & 92 & & 63 & - & 155 & 0 \\
\hline TOT & & 131 & 11 & 299 & 27 & 430 & 38 \\
\hline
\end{tabular}

Tabla 1. Listado taxonómico del conjunto arqueofaunístico hallado en la excavación del Cuarto 4 y exterior del Cuarto 3 del Palacio 6J2 de La Blanca. 
La fauna se encuentra dominada por los mamíferos (74\% NISP), seguida por aves (14\%), reptiles (11\%) y peces (1\%) (Figura 5). Entre los animales más abundantes se encuentran los tepezcuintles (11.63\% NISP) y los venados (10.23\% NISP). En ambos casos se trata de animales cuya carne suele ser altamente valorada y que habitan en los bosques, acercándose a las milpas, por lo que su captura apunta a un aprovechamiento de áreas cercanas al asentamiento. Destacan también otros mamíferos, como los pecaríes (6.53\% NISP), y reptiles, como las tortugas de pantano (6.53\% NISP); ambos animales pueden alcanzar grandes tallas y seguramente se obtuvieron en áreas cercanas a La Blanca. Las tortugas pudieron haber sido capturadas en las cercanías del río Salsipuedes o en las lagunas del entorno, mientras que los pecaríes pudieron encontrarse fácilmente en las milpas cercanas al asentamiento. La fauna minoritaria estuvo compuesta por peces, que incluyen mojarras y bagres, así como pavos, perros, tapires y pumas.

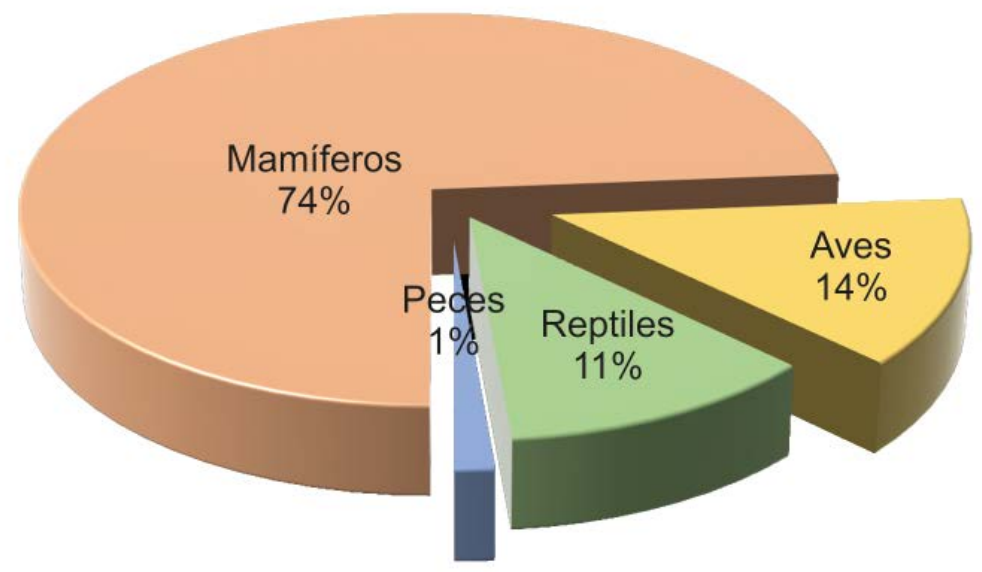

Figura 5. Distribución taxonómica de los restos de animales de La Blanca.

En los dos conjuntos estudiados se observan diferencias en cuanto a la presencia de ciertas especies. Así, la fauna hallada frente al umbral del Cuarto 3 se caracteriza por la presencia de fauna silvestre y doméstica común. Es en este espacio en donde se registran únicamente restos de animales como perros y tortugas lagarto. Por su parte, en el interior del Cuarto 4 se observa una diversidad más amplia tanto de la fauna doméstica como silvestre representada por animales tan variados como peces, diferentes especies de tortugas, pecaríes, tapires y coatíes.

\subsection{Ritualidad animal en La Blanca}

El interés por el estudio de los rituales no escapa a la disciplina zooarqueológica ya que estas actividades suelen estar presentes en la celebración de banquetes 
y ofrendas en donde los animales jugaron un papel relevante (Pohl, 1983: 55; Koželsky, 2005: 86-89). Sin embargo, en ocasiones resulta problemático caracterizar la actividad ritual con base en un conjunto arqueofaunístico, ya que las implicaciones zooarqueológicas de los rituales dependerán de las funciones de los animales en actividades de este tipo. Por ello, en este trabajo utilizamos el acercamiento teórico propuesto por Emery (2004), en el que se sugiere que la identificación del simbolismo ritual de los animales debe tomar en consideración dos esferas de identificación: la del contexto arqueológico y la del contexto taxonómico. Aunado a estas directrices, consideramos fundamental la inclusión de las identificaciones tafonómicas como registro de la modificación cultural en la fauna posiblemente ofrendada.

\section{Identificación del contexto arqueológico}

Como ya hemos apuntado, la hipótesis de partida era que los materiales arqueofaunísticos objeto del estudio correspondían a un ritual llevado a cabo en algún momento del Clásico Terminal, motivado por el abandono del sitio. Sin embargo, debido a que existieron ocupaciones posteriores, los contextos fueron removidos, de ahí que resultaba complicado diferenciar entre las actividades rituales o de consumo que pudieron haber realizado los diferentes grupos humanos que ocuparon las estancias palaciegas a lo largo del tiempo.

En este sentido, los depósitos de la fauna del Cuarto 4 o Cuarto de los Grafitos son los más abundantes en la muestra estudiada y son, quizá, los más susceptibles de presentar confusiones en cuanto a su caracterización como elementos rituales. Un caso similar ocurrió en las excavaciones de Miguel Orrego en el Grupo G de Tikal donde las acumulaciones de huesos animales en el piso de una estancia fueron resultado de actividades de consumo por pobladores posteriores que habitaban encima de la estructura abandonada, ocasionando problemas de interpretación (véase Pohl, 1976: 66, 67). Es por esto que nuestro acercamiento a la fauna de La Blanca incluye tres dimensiones identificativas (contexto arqueológico, taxonómico y tafonómico), las cuales nos permitirán profundizar en la caracterización del significado de la presencia animal en los contextos analizados, con el fin de discernir entre actividades rituales y de consumo posterior.

Los restos de fauna estudiados fueron hallados tras la excavación del nivel de derrumbe que cubría el interior de esta estancia, en el centro del pasillo que se extiende longitudinalmente entre la banqueta y el muro sur. Se encontraban en un potente estrato compuesto por abundante ceniza y carbones, pesas de red y un caparazón completo de tortuga que se deshizo tras su exhumación (Suboperación 27/Lote 2), debajo de un sillar caído con representación de grafitos (Vidal, 2006: 13-14) (Figura 6). De la excavación del derrumbe que cubría este contexto se recuperaron numerosos fragmentos cerámicos pertenecientes al Clásico Terminal y al Posclásico Temprano. A pesar de la problemática que podría representar el contexto, sobre todo por la coexistencia de materiales pertene- 
cientes a dos periodos diferentes, la presencia de fauna en un cuarto en cuyos muros abundan los grafitos que representan animales parece sugerir algún tipo de intencionalidad en su depósito. Además, el conjunto faunístico asociado a este lote presenta similitudes con otros depósitos de ofrendas terminales, que se han registrado en sitios como Piedras Negras y Cerros (Coe 1959: 94; Garber, 1989: 9). Estos depósitos, en principio, representarían, como sugiere Harding (2006: 123), acciones cuyo propósito era reescribir significados en los edificios y espacios, pero a su vez indican la destrucción y la desactivación de estructuras obsoletas. Por otro lado, la presencia de tales restos en espacios habitacionales podría indicar, a su vez, la práctica de actividades rituales privadas (Vogt, 1993).

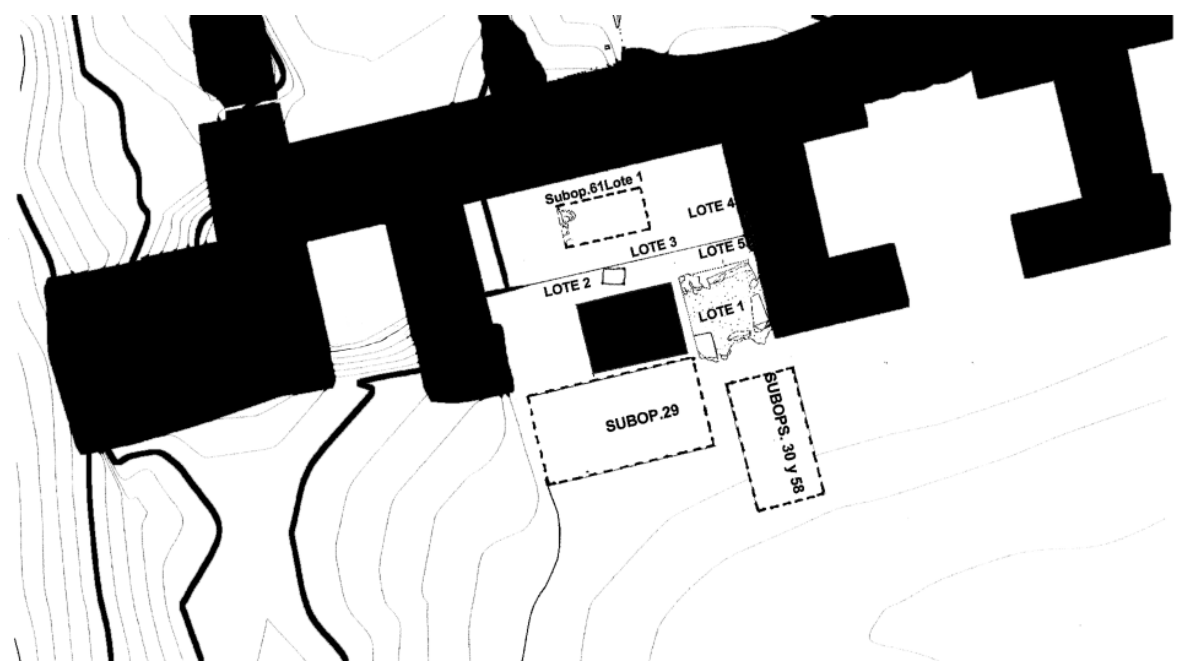

Figura 6. Planta del Cuarto 4 del Palacio 6J2 con indicación de la excavación del Lote 2 en que apareció el conjunto faunístico (Proyecto La Blanca, 2005).

En cuanto a los restos óseos animales hallados en el exterior del Cuarto 3, éstos proceden de la excavación del derrumbe que cubría el acceso a dicha estancia. Para liberar este frente se plantearon tres trincheras de aproximación (Suboperaciones 36, 38 y 43). El conjunto de huesos que nos ocupa apareció en la primera de ellas (Suboperación 36/ Lote 1) (Figura 7). Los restos esqueléticos no presentaban ninguna conexión anatómica y fueron depositados a escasa distancia de la entrada del cuarto junto con otros vestigios líticos. Algo más hacia el oriente y junto a la grada de acceso al cuarto, en la Suboperación 43, se documentó el Lote 1 , integrado por una pequeña vasija cerámica completa, un cuchillo de pedernal, otros restos líticos y tres fragmentos de una figurita antropomorfa. Todos estos materiales fueron adscritos al periodo Clásico Terminal, en esta ocasión sin duda alguna, debido a que de estas trincheras se recuperaron 4600 fragmentos cerámicos de ese periodo, y sólo ocho posclásicos (Vidal, 2006: 17-18). 

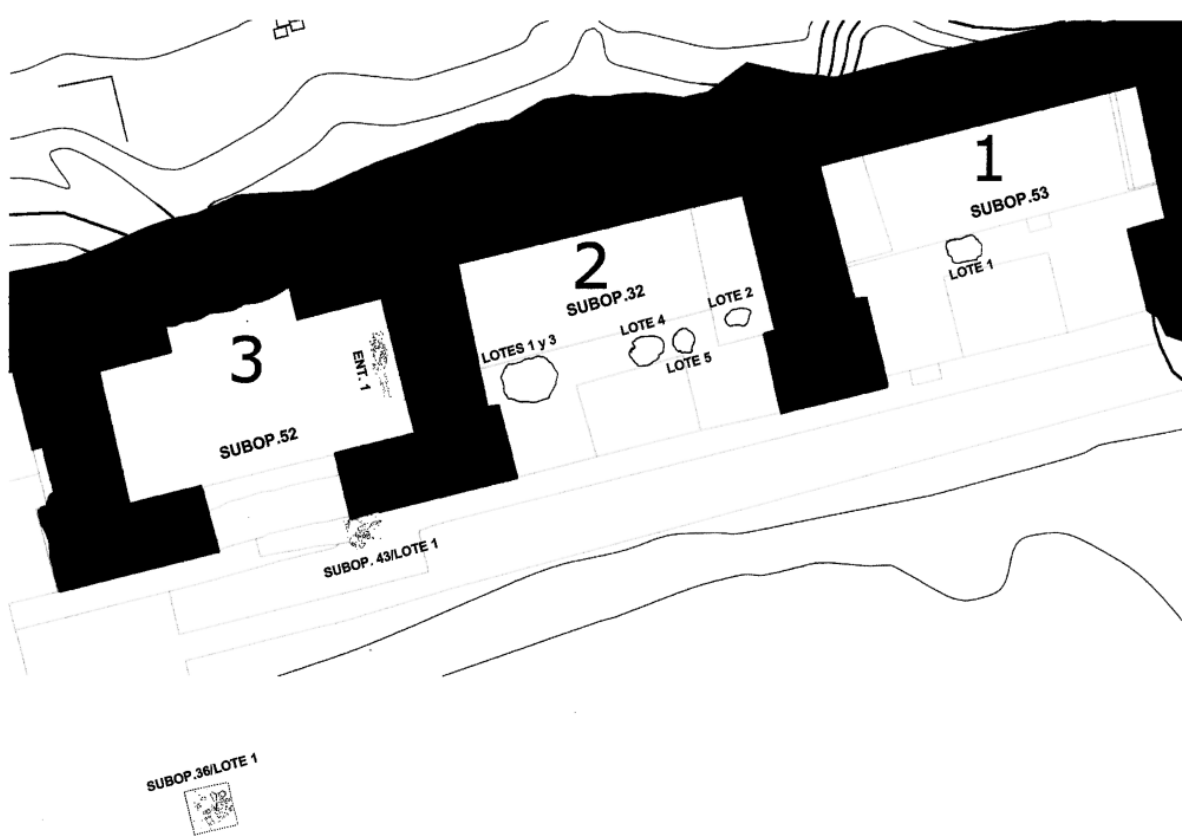

Figura 7. Planta de los Cuartos 1, 2 y 3 del Palacio 6J2, con indicación de los diversos lotes (ofrendas) hallados en su interior y de la Suboperación 36/Lote 1, situada frente al Cuarto 3

(Proyecto La Blanca, 2005).

En definitiva, aunque el contexto de ambos lotes con restos de fauna sugería su adscripción a algún tipo de actividad ritual coincidente con el abandono del sitio, aún faltaba por determinar el contenido taxonómico y tafonómico de la fauna, algo fundamental para conocer posibles intencionalidades rituales en los contextos de derrumbe de ambos sectores del ala sur del Palacio 6J2.

Identificación taxonómica y tafonómica

En primer lugar, para poder identificar la posibilidad de las actividades rituales a partir de datos zooarqueológicos, resultaba necesario hacer una revisión de las especies presentes en el conjunto faunístico de ambos lotes, con el fin de conocer si en la muestra había fauna particularmente importante dentro de la cosmovisión maya. Su análisis y estudio nos permitió reconocer en ambos casos la presencia de fauna silvestre y doméstica (Tabla 1 y Figura 5), pudiéndose identificar ciertos taxones que se asocian tradicionalmente, ya sea por su singularidad o amplio aprovechamiento, al corpus de animales simbólicos de los mayas prehispánicos.

Así, dentro de la fauna silvestre se identificaron animales que destacan en el conjunto arqueofaunístico porque se les asocia con un carácter sagrado, y que además aparecieron de forma restringida en nuestra muestra, por lo que 
su presencia apuntaría a la posibilidad de algún tipo de actividad ritual. El caso más sobresaliente es el de los grandes felinos, de los cuales fueron identificados restos de puma (Puma concolor) en el Cuarto 4. Por lo general, los felinos en el área maya estaban asociados a rituales dinásticos de la élite debido a su fortaleza y habilidades como cazadores, lo que aunado a su piel les confería un halo de realeza (Peterson, 1990; Roys, 1965; Saunders, 1994).

Los restos de puma del Cuarto 4 (Figura 8) estaban compuestos por elementos de una pata delantera izquierda (tercer metacarpo y primera falange) y de una pata trasera derecha (segundo metatarso).

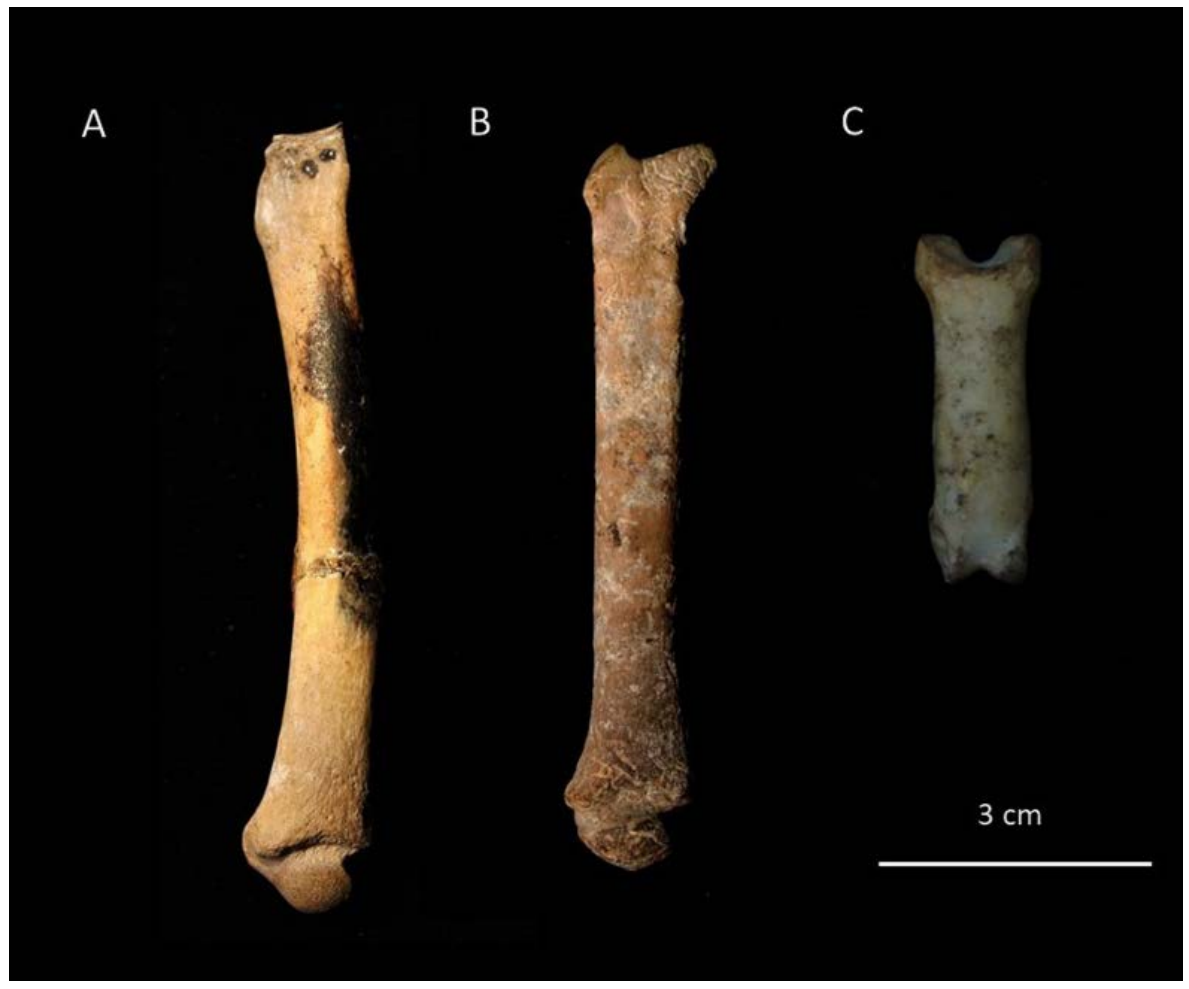

Figura 8. Restos óseos de puma (Puma concolor) recuperados del Cuarto 4 del Palacio 6J2 de La Blanca. A) segundo metatarso derecho, B) tercer metacarpo izquierdo, C) primera falange (Fotografía de Nayeli Jiménez).

Dos de estos elementos se encontraban quemados, el metatarso con evidente coloración negra en la diáfisis y el metacarpo con una coloración marrón oscuro en la epífisis distal, estando ambas marcas ocasionadas por el contacto directo con el fuego. Cabe destacar que, de estos elementos, el hueso de la pata delantera (Figura $8 \mathrm{~A}$ ) fue encontrado en el Lote 2 , mientras que los otros dos restos se 
encontraron algo más alejados, pero siempre dentro del mismo estrato. Es muy posible que los tres restos pertenezcan a un mismo individuo, ya que las dimensiones de los fragmentos corresponden a un individuo de una talla similar. Por otro lado, se observa que el metatarso del Lote 2 tiene menos afectaciones tafonómicas naturales como la erosión y marcas de raíces, patentes en el metacarpo y falange del derrumbe. Esto nos invita a pensar que, aunque se haya realizado una actividad ritual con las patas de los pumas, este contexto fue posteriormente removido. En este sentido, es importante destacar la presencia de animales como tepezcuintles y zarigüeyas que, aunque en el caso de los primeros son valorados por su aporte cárnico, son también considerados agentes tafonómicos intrusivos, ya que suelen ocupar espacios desocupados para hacer sus madrigueras, alterando así los contextos originales.

Consideramos, por tanto, que la presencia de elementos esqueléticos de patas de pumas corresponde a la colocación intencionada de estos miembros corporales - pata delantera y trasera-, como parte de una ofrenda en la que el fuego también fue partícipe, tal como lo evidencian las marcas de afectaciones térmicas en los huesos, y que con posterioridad este contexto fue alterado por fauna intrusiva.

Conviene recordar que la literatura arqueológica menciona que en el área maya existió una preferencia hacia las patas de jaguares y pumas en contextos de élite rituales, como en Palenque, Piedras Negras, Dos Pilas, Becán y Caracol, así como en enterramientos en Mayapán (Vargas, 2012: 108). En otros asentamientos mayas, como Ek Balam, se han identificado patas de jaguares que además presentaron marcas de corte, posiblemente como resultado del descarnamiento para obtener la piel (Vargas, 2012: 130). Por su parte, los restos de puma de La Blanca carecen de tales marcas, por lo que no podríamos sugerir la colocación exclusiva de la piel en esta ofrenda sino de las patas y con ellas sus garras como símbolo de poder elitista.

Otros animales salvajes identificados fueron los venados, alimento preferido de la élite (Pohl, 1983: 466; Montero, 2009: 54-56). Además de su amplia utilización como recurso alimenticio, los venados tenían una fuerte carga simbólica dentro del pensamiento mítico-religioso de los antiguos mayas, ya que se les identifica como símbolos de fertilidad y se relacionan por lo general con el renacimiento asociado a la élite, pero también a otros elementos como el sol y el fuego, la lluvia y las sequías (Pohl, 1981: 516).

En nuestras muestras, destaca la presencia de venado cola-blanca en ambos contextos. En el Cuarto 4 registramos elementos craneales y post-craneales en buen estado de conservación y con marcas de quemado en un $40 \%$ de la muestra (Figura 9), que indican la acción directa de fuego.

En lo que respecta a las marcas tafonómicas de los restos de venado del exterior del Cuarto 3, destacan los restos de venado cola-blanca afectados por el fuego y que representaron un $14.30 \%$ del total de este taxón. Otras marcas tafonómicas encontradas en huesos de venado, aunque en menor representación, 


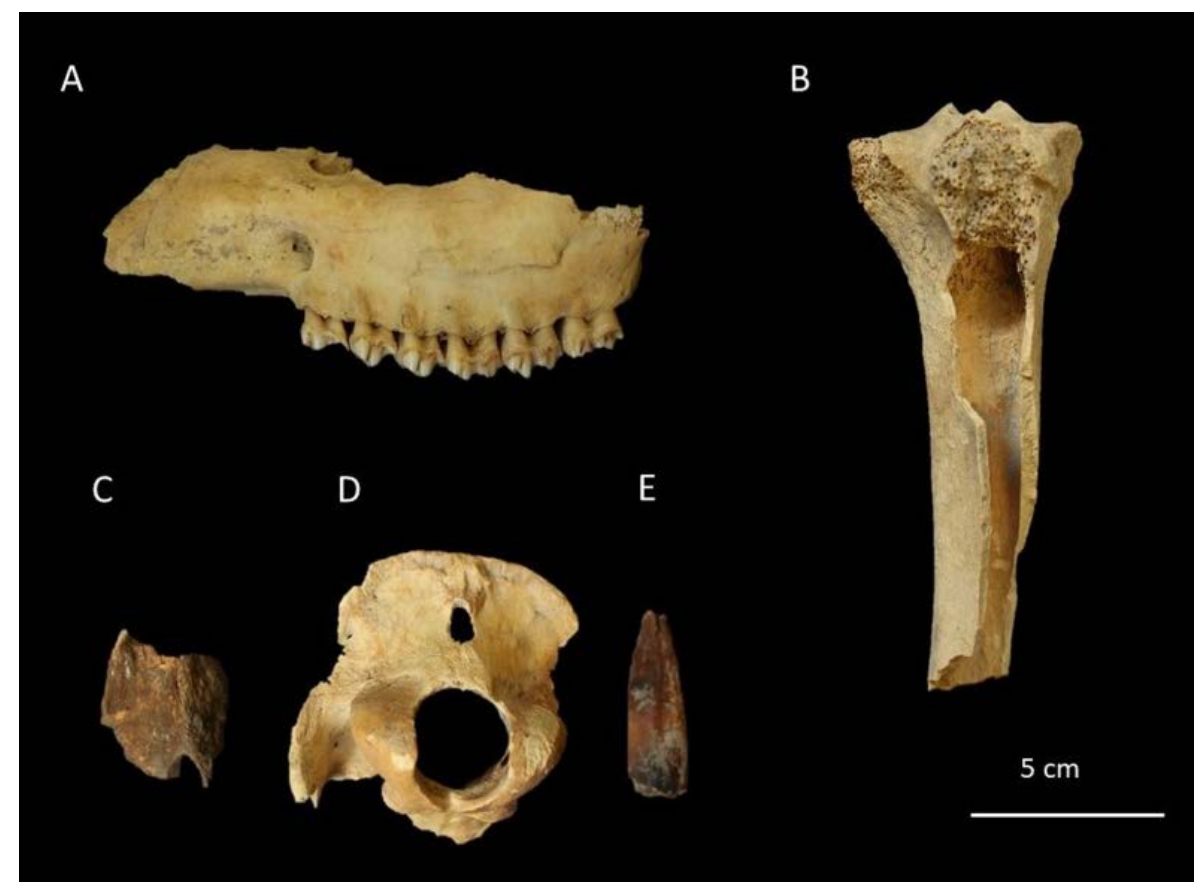

Figura 9. Elementos esqueléticos de venado cola blanca:

A) maxilar izquierdo, B) tibia derecha, C) tibia izquierda, D) basioccipital,

E) fragmento de asta (Fotografía de Nayeli Jiménez).

fueron las que indican masticación por carnívoros y fracturas que testimonian su consumo como alimento, así como las de manufactura de artefactos óseos (véase epígrafe 3.2). Esto permite sugerir el carácter utilitario de los venados y sus restos en este espacio.

Es posible, por tanto, que la utilización del venado cola-blanca en ambos contextos responda a actividades distintas. Por una parte, los restos del Cuarto 4 o Cuarto de los Grafitos, parecen sugerir que fueron depositados a modo de ofrenda, mientras que los del exterior del Cuarto 3 apuntan a un posible aprovechamiento utilitario, es decir, al consumo de alimentos como parte de un ritual relacionado con el cese de actividad en este palacio. El carácter ritual de los venados en el Cuarto 4 parece reforzarse por las evidencias de fuego asociados al sillar y porque además este cuarto está decorado con grafitos con representaciones animales, entre los que destaca la figura de un venado con las patas delanteras juntas y la lengua fuera (Figura 10).

La importancia del venado no sólo se restringe a su consumo, altamente apreciado por la élite maya prehispánica, sino que también su cacería tiene una relevancia dentro de la cosmovisión. Así, la caza de este animal era considerada 


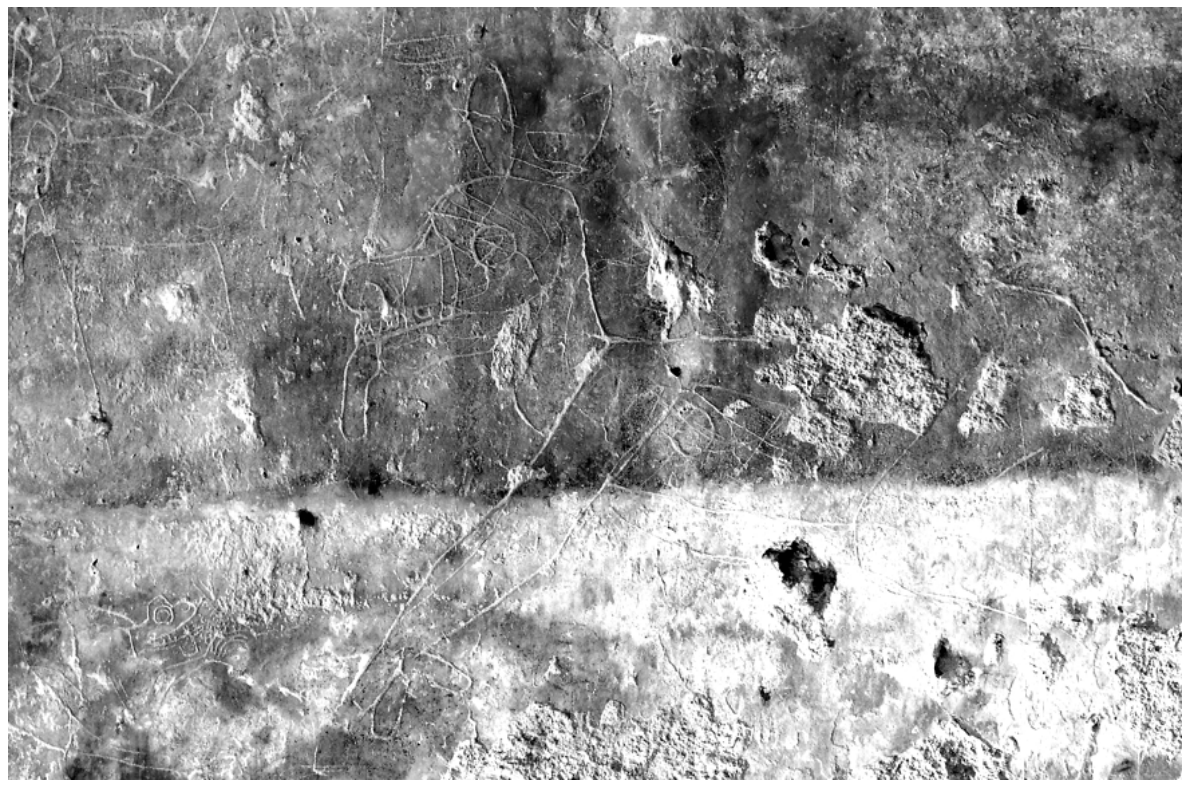

Figura 10. Grafito del Cuarto 4 del Palacio 6J2 de La Blanca representando un venado (Fotografía de Gaspar Muñoz Cosme).

una actividad sagrada que denotaba el poder simbólico de los venados para los antiguos mesoamericanos, simbolizando la guerra y el poder, pero también un acto de regeneración (Dehouve, 2009: 309; Montero, 2009: 53; Seler, 1996: 218219). De hecho, el grafito de este cuarto que representa un venado debió formar parte de una escena de caza y aunque no se ha conservado hasta nuestros días, tanto la postura del animal como el hecho de que lleva la lengua fuera sugieren que está corriendo delante de su cazador o cazadores.

Otros animales domésticos, como los perros, dotados de un acusado carácter simbólico, también se encontraron en nuestros contextos, concretamente en el entorno del Cuarto 3. La muestra se restringe a la presencia de una tibia de un individuo adulto, sin marcas tafonómicas que indiquen algún tipo de manejo cultural salvo marcas de raíces debido al contacto con el sedimento. A pesar de que un solo resto de este taxón no representa evidencia suficiente para indicar alguna actividad ritual, resulta interesante que pertenezca al mismo lote que el resto de los huesos animales. De hecho, la presencia de patas traseras de perro, también sin marcas de corte, junto con una garra de jaguar, en el conjunto arqueozoológico hallado en las excavaciones del Templo XIX de Palenque, fue interpretada como una ofrenda durante algún evento ritual (Varela, 2017: 158, 165). Por otro lado, en sitios del Petén guatemalteco, como Ceibal, se han encontrado restos de 
perros sin marcas tafonómicas aparentes pero cuya firma isotópica corresponde a las Tierras Altas, lo cual indicaría un comercio de estos animales con fines rituales desde el Preclásico (Sharpe et al., 2018: 3607). Con ello, no sugerimos que sea el caso del resto de perro encontrado en el Cuarto 3, pero nos indica la importancia y procuración de estos animales y de sus restos sin aparentes marcas tafonómicas, lo que aunado a los restos del venado antes mencionados y a la presencia de otras ofrendas en el umbral del cuarto parece contribuir a corroborar la hipótesis de la celebración de un ritual durante el cual se consumieron alimentos, como consecuencia del abandono del sitio.

Adicionalmente, los pecaríes, animales comúnmente consumidos en banquetes de la élite y otros estratos sociales (Fridberg, 2005), también fueron identificados en este estudio. Resulta interesante que en ambos contextos los pecaríes, adultos y sub-adultos, únicamente estuvieron representados por los elementos craneales, sobre todo mandíbulas con marcas de afectaciones térmicas directas (Figura 11).

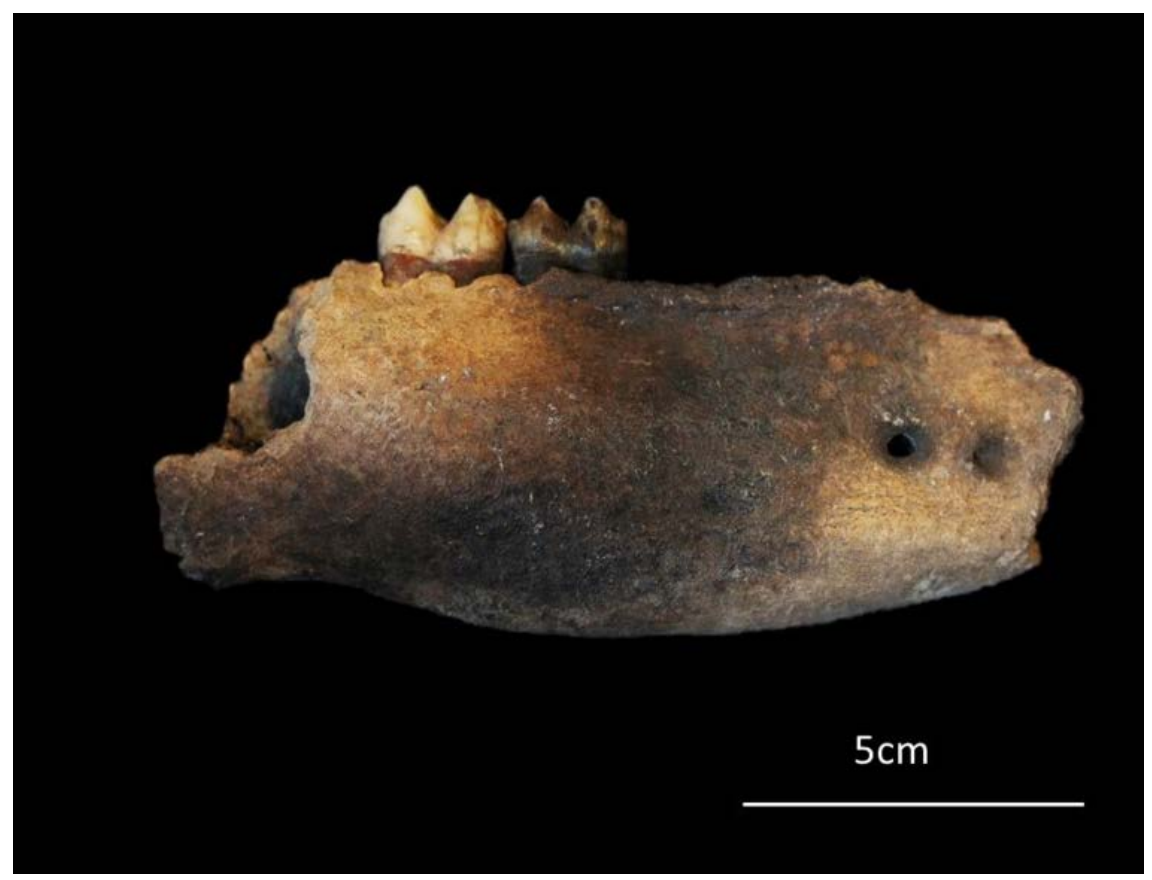

Figura 11. Mandíbula de pecarí recuperada del Cuarto 4 con marcas de afectaciones térmicas (Fotografía de Nayeli Jiménez).

En este sentido, es importante destacar las representaciones de pecaríes en las vasijas polícromas mayas, donde suelen aparecer involucrados en actividades rituales, antropomorfizados o en compañía de otros seres sobrenaturales (Fridberg, 2005: 2-3). En ocasiones se les representa con volutas que emergen de los 
orificios nasales, portando una bufanda o un collar de ojos (véanse, por ejemplo, las vasijas K1001, 1203, 1743). Son los llamados "pecaríes de fuego" (Grube y Nahm, 1994: 698), y hay quien ha querido ver en dichas volutas de fuego representaciones gráficas del aullido emitido por los individuos durante el proceso de transformación en sus wayob a través de la intoxicación ritual, lo que explicaría que en algunas imágenes aparezcan pecaríes asociados a enemas, como ocurre en la vasija K7525 (Fridberg, 2005: 26). También hay algunos ejemplares de vasijas tetrápodes cuyos soportes simulan cabezas de pecarí (K2866); de hecho, en otra ofrenda procedente del Cuarto 4 del Palacio 6J2 de La Blanca (Suboperación 27/Lote 1), se encontró un cántaro cuyos soportes zoomorfos, aunque incompletos, parecen sugerir que son del tipo patas-pecarí (Vidal, 2006: fig. 5). Finalmente, también es interesante recodar la escena en la que aparecen un venado y un pecarí en una procesión de cazadores, sostenidos por seres humanos (K414) con la intención, aparentemente, de ser conducidos a un sacrificio ritual, relacionado con la fertilidad y la prosperidad agrícola (Pohl, 1981; Fridberg, 2005: 29). Todo ello contribuye a reforzar la hipótesis de actividades rituales.

Por otro lado, el mundo acuático estuvo también representado en el conjunto zooarqueológico del Palacio 6J2. Los restos de peces, pez blanco, mojarras y bagres de agua dulce, aunque en números escasos, proceden del Cuarto 4 y también presentaron marcas de afectaciones térmicas (Figura 12).

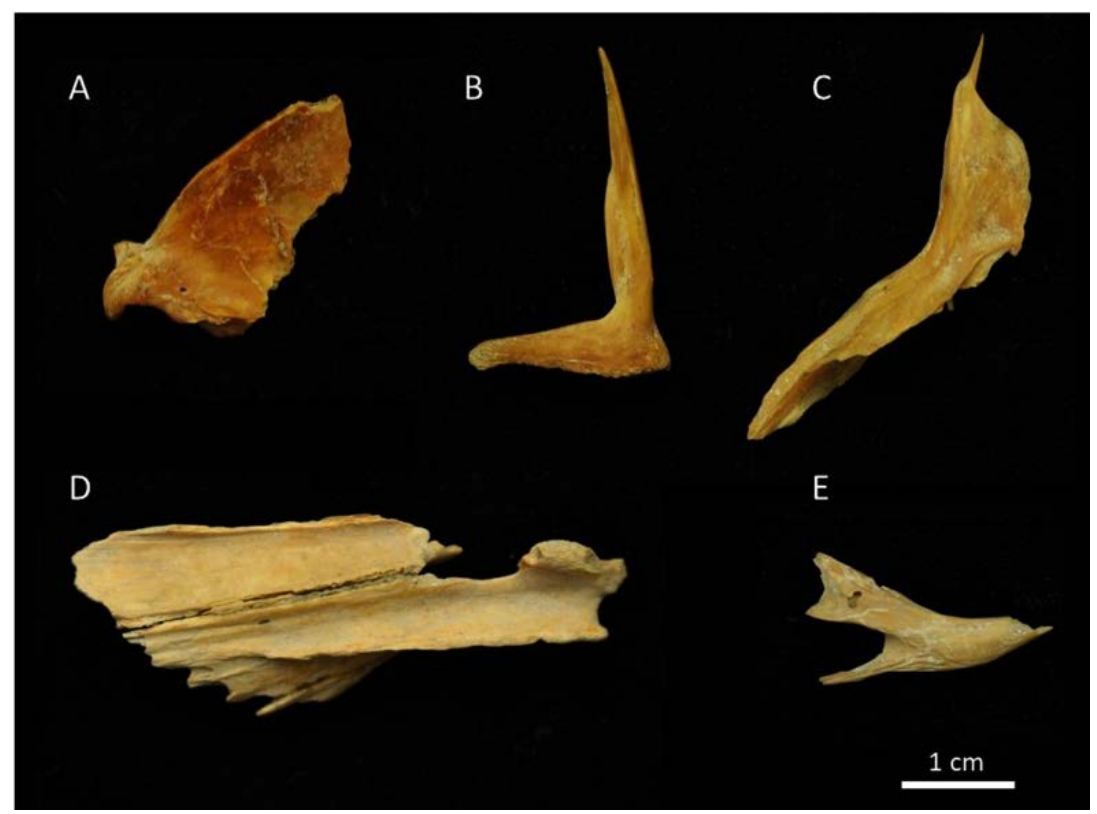

Figura 12. Restos de peces recuperados en el Cuarto 4: A) cuadrado de mojarra, B) dentario de pez blanco, C) cleitro de pez blanco, D) cleitro de bagre de agua dulce, E) cleitro de bagre de agua dulce (Fotografía de Nayeli Jiménez). 
De manera interesante estos restos se encontraron asociados a pequeñas pesas cerámicas de red (Vidal, 2006: 14), las cuales parecen no haber sido utilizadas muy frecuentemente debido a sus bordes filosos. Otros elementos del mundo acuático que acompañan a nuestra muestra incluyen restos de tortugas de río que, al igual que los peces, son testimonio de la importancia de los recursos acuáticos para la subsistencia, sin olvidar su protagonismo en los mitos relativos a la renovación del cosmos y la regeneración de la vida (Lucero, 2006; Vidal y Rivera, 2017: 82-83).

De acuerdo con las identificaciones taxonómicas y tafonómicas para determinar las actividades rituales, hemos observado que en el Palacio 6J2 de La Blanca el fuego ocupa un papel de suma importancia en el aparente simbolismo ritual asociado a los animales. Es posible que el fuego como elemento fundamental en estas actividades haya representado el acto final de destrucción y regeneración de los recursos animales.

Además, el fuego ha sido interpretado como un aspecto de la guerra, la muerte y el renacimiento del que forman parte diversas ofrendas rituales (Brady y Colas, 2005: 160; Chinchilla, 2018: 45; Nájera, 2020: 113). En este sentido llama la atención la cantidad de elementos faunísticos con marcas de afectaciones térmicas en este sector del Palacio 6J2. De esta manera, un 15\% de la fauna total y más de un $60 \%$ de la fauna con afectaciones tafonómicas (Figura 13) presentó marcas de quemado por acción directa del fuego que en algunos casos incluyó la calcinación. Tales marcas se concentraron sobre todo en la fauna del Cuarto 4 , y se extienden a animales como pecaríes, tapires, pumas y venados. Es muy probable que en estas actividades rituales el fuego haya actuado como elemento destructor, pero también dador de vida. Y quizá se hayan realizado plegarias a modo de agradecimiento al ambiente natural proveedor de recursos, pero solicitando al mismo tiempo los beneficios de una nueva etapa que estos pobladores habrían de enfrentar. Además, la evidencia de huesos de animales y artefactos quemados en estancias privadas acompañados por artefactos con poco uso o "matados" ha sido identificada en otros contextos arqueológicos del área maya como una de las características de los rituales de terminación (Stanton, Brown y Pagliaro, 2008: 237-238). Mientras que los huesos animales quemados también se asocian a ofrendas relacionadas con la cacería en el Petén guatemalteco en épocas actuales (Brown, 2004: 37; Brown y Emery, 2008: 324-325).

Otras marcas tafonómicas encontradas en el conjunto arqueofaunístico de La Blanca fueron las modificaciones ocasionadas por acción de otros animales y que incluyen roído por roedores y masticación por carnívoros. En ambos casos estas marcas representaron poco más del $25 \%$ de las marcas tafonómicas.

Los restos con marcas de erosiones patentes a causa de exposiciones ambientales o intemperización fueron relativamente escasos (cerca de un 10\% en ambos cuartos). Esto es indicativo de una ubicación mayoritaria de los restos en ambientes cerrados o protegidos, si bien recordemos que los restos faunísticos del Cuarto 3 fueron encontrados en el exterior de éste, frente al vano sur. Las 


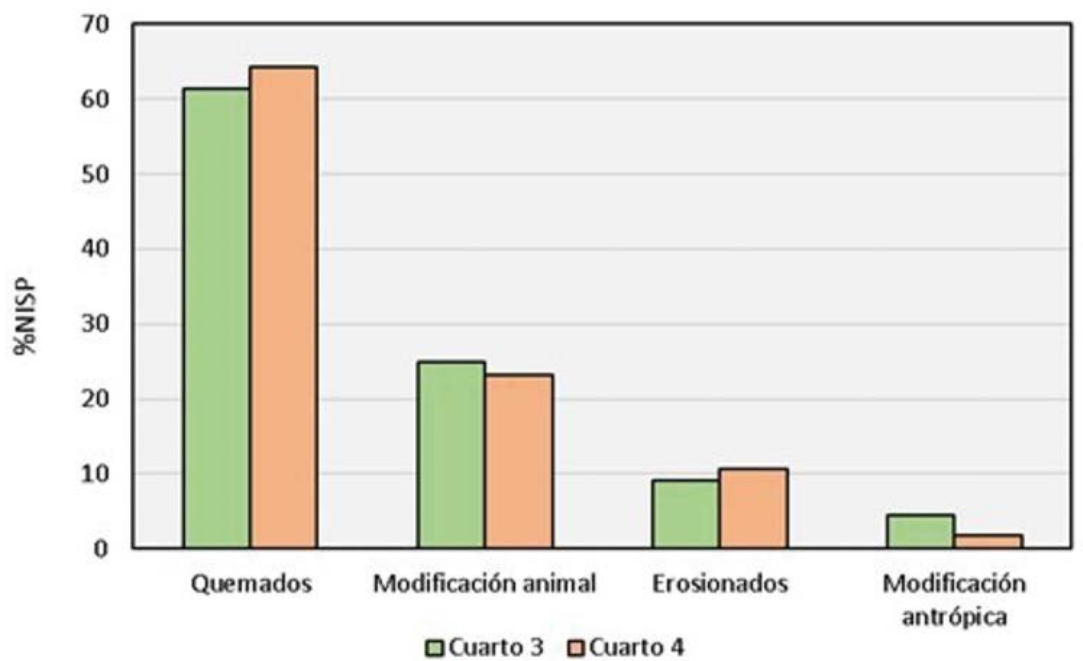

Figura 13. Proporción de las modificaciones tafonómicas en las muestras zooarqueológicas del Palacio 6J2.

marcas de intemperización de este cuarto, además, nos sugieren que los restos estuvieron un tiempo expuestos. En contextos como el basurero de Lagartero tales marcas ayudaron a identificar prácticas de consumo alimentario posiblemente ritual a través de la acumulación en las afueras de las estancias (Koželsky, 2005: 277).

\subsection{Huellas de fabricación en hueso animal}

Por otro lado, entre la colección de fauna estudiada se encontraron restos de hueso de animales trabajados, aunque en una proporción mucho menor que en otras modificaciones ( $4.55 \%$ en el Cuarto 4 y $1.79 \%$ frente al Cuarto 3 ). La presencia de estas alteraciones en los contextos del Palacio 6J2 resulta relevante debido a que podría dar luz sobre procesos tecnológicos de producción de artefactos o herramientas de hueso animal en La Blanca.

De acuerdo con el modelo de producción de artefactos de hueso propuesto por Emery (2009), los restos de nuestro estudio representaron tanto residuos del tallado de artefactos de hueso como de la reducción secundaria (Figura 14). La muestra estuvo compuesta por una epífisis distal de un fémur de coatí, que representa el residuo del tallado de este elemento para fabricar algún artefacto. Por su parte, la reducción secundaria se encontró representada por un metatarso de venado cola-blanca, con evidencias de haber sido seccionado de manera longitudinal y posteriormente pulido en la cara medial. 


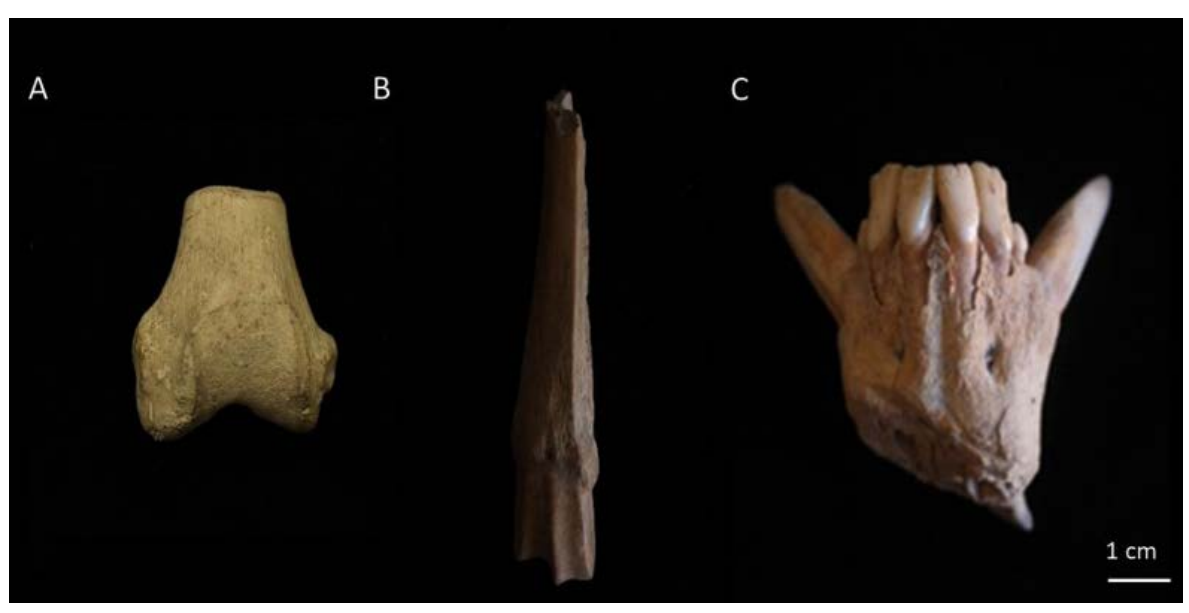

Figura 14. Elementos esqueléticos trabajados: A) residuo primario de diáfisis de fémur de coatí, B) reducción secundaria de metatarso de venado cola blanca y C) mandíbula de pecarí con corte basal e incisiones dentales (Fotografía de Nayeli Jiménez).

Ambos elementos, tanto la epífisis como el metatarso, corresponden a preformas de huesos de animales trabajados, característicos del área maya. Formas similares, identificadas como desechos de talla, han sido identificadas por autores como Emery y Aoyama (2007), Emery (2009) y Newman (2013) en estancias de la élite del periodo Clásico en Aguateca y El Zotz.

Otro elemento interesante en nuestro estudio fue la presencia de una mandíbula de pecarí cortada basalmente y con incisiones antrópicas en los incisivos centrales. No se ha determinado a qué podría corresponder este tratamiento, pero el corte basal posiblemente fue realizado con una herramienta de gran calibre para permitir separar este hueso robusto.

\section{Conclusiones}

La fauna encontrada en el ala sur del Palacio 6J2 de La Blanca resultó ser una importante herramienta para identificar actividades rituales llevadas a cabo en este sector del palacio. A pesar de tratarse de una muestra pequeña, las caracterizaciones del contexto, así como las identificaciones taxonómicas y tafonómicas hicieron posible corroborar la hipótesis de partida de que corresponden a actividades rituales. En ellas, los animales eran dotados de un carácter sagrado y el fuego habría jugado un papel importante, representando el proceso de regeneración coincidente con el abandono del asentamiento.

Todas las evidencias apuntan a que las agrupaciones de fauna del Cuarto 4 corresponden a una ofrenda de terminación realizada a raíz del abandono 
del sitio en el Clásico Terminal, mientras que los restos encontrados frente al Cuarto 3 pudieron haber formado parte de un banquete ritual celebrado tras el depósito de diversas ofrendas en el interior de los cuartos de este sector del palacio (véanse Figuras 6 y 7), que incluyó el consumo de animales como recurso alimenticio. Avalamos así nuestra hipótesis planteada durante el trabajo de campo, de que estos depósitos no eran desechos de ocupantes de época posterior, sino que estuvieron estrechamente vinculados con eventos rituales como consecuencia del abandono del sitio. El que insistamos en este hecho se debe a que tradicionalmente muchos depósitos similares hallados en contexto de élite han sido interpretados de acuerdo con la primera opción, es decir, como simples desechos realizados por pobladores "sacrílegos", sin tener en cuenta la posibilidad de que haya existido otro tipo de intencionalidad ritual, tal como sostienen Stanton, Brown y Pagliaro (2008: 242). Además, las evidencias tafonómicas y taxonómicas del Cuarto 3 se asemejan a los patrones faunísticos encontrados en sitios como Lagartero, donde la concentración de huesos fuera de una estructura de élite sugiere su utilización para la práctica de banquetes rituales (Koželsky, 2005: 77-78).

Asimismo, los restos de fauna de La Blanca representan la explotación del bosque circundante e indica una captura y consumo de animales con elevado valor cárnico, como los venados y pecaríes. La explotación de los escenarios cercanos también incluye el aprovechamiento de las aguadas y ríos cercanos, tal como lo demuestra la presencia de tortugas y peces.

En definitiva, a partir del estudio de este conjunto arqueofaunístico fue posible caracterizar las actividades rituales y de subsistencia en un sector de la Acrópolis de La Blanca. La continuación del análisis y estudio de los restos de fauna recuperados en otras estructuras y contextos de este sitio arqueológico permitirá profundizar aún más en la utilización de las diversas especies animales en este territorio de valles fluviales del Petén guatemalteco, así como su función en los rituales, lo cual constituye un tema novedoso para la región.

\section{Agradecimientos}

Las autoras agradecen expresamente el patrocinio del Ministerio de Educación, Cultura y Deporte de España, a través de la financiación obtenida por el Proyecto La Blanca y su entorno, dentro del programa de ayudas para Proyectos Arqueológicos en el Exterior, así como del Ministerio de Innovación, Ciencia y Universidades, a través de la financiación de los proyectos de investigación coordinados con números de referencia BIA2011-28311-C02, BIA2014-53887-C2 y PGC 2018098904-B-C22 sobre Arte y Arquitectura maya. Nuevas tecnologías para su estudio y conservación, de la Fundación Palarq, y el apoyo del Ministerio de Cultura y Deportes de Guatemala, que han contribuido de forma determinante a hacer posible esta investigación. Los análisis zooarqueológicos se realizaron con el patrocinio 
del Consejo Nacional de Ciencia y Tecnología de México, a través del programa Becas Conacyt para estudios doctorales en el extranjero (Beca Conacyt 215047). Las autoras agradecen especialmente a Ashley Sharpe y Fabiola Morales Mejía por la corroboración en la identificación de los elementos esqueléticos de puma; al Dr. Arturo Morales Muñiz por sus amables comentarios durante la identificación del material y el acceso a las colecciones de referencia del Laboratorio de $\mathrm{Ar}$ queozoología de la Universidad Autónoma de Madrid, y a los revisores anónimos de esta contribución por sus valiosas sugerencias.

\section{BIBLIOGRAFÍA}

Brady, James E. y Pierre R. Colas

2005 '“Nikte' Mo' Scattered Fire into the Cave of K'ab Chante'. Epigraphic and Archaeological Evidence for Cave Desecration in Ancient Maya Warfare", Stone Houses and Earth Lords. Maya Religion in Cave Context, pp. 149-166, Keith M. Prufer y James E. Brady (eds.). Boulder: University Press of Colorado.

Brown, Linda A.

2004 "Dangerous Places and Wild Spaces: Creating Meaning with Materials and Space at Contemporary Maya Shrines on El Duende Mountain”, Journal of Archaeological Method and Theory, 11 (1): 31-58. Dol: https://doi.org/10.1023/ B:JARM.0000014347.47185.f9.

Brown, Linda A. y Kitty F. Emery

2008 "Negotiations with the Animate Forest: Hunting Shrines in the Guatemalan Highlands", Journal of Archaeological Method and Theory, 15 (4): 300-337. Dol: https://doi.org/10.1007/s10816-008-9055-7.

Chinchilla Mazariegos, Oswaldo

2018 "Fire and Sacrifice in Mesoamerican Myths and Rituals", Smoke, Flames, and the Human Body in Mesoamerican Ritual Practice, pp. 29-53, Vera Tiesler y Andrew K. Scherer (eds.). Washington, D. C.: Dumbarton Oaks Research Library and Collection.

Clason, Antje T.

1972 "Some Remarks on the Use and Presentations of Archaeological Data", Hellinum, 12: 139-153.

Coe, William R.

1959 Piedras Negras Archaeology Artifacts, Caches and Burials. Philadelphia: University Museum, University of Pennsylvania.

Dehouve, Danièle

2009 "Un ritual de cacería. El conjuro para cazar venados de Ruiz de Alarcón", Estudios de Cultura Náhuatl, 40: 299-331. 
Emery, Kitty F.

2004 "Animals from the Maya Underworld: Reconstructing Elite Maya Ritual at the Cueva de los Quetzales, Guatemala”, Behaviour Behind Bones: The Zooarchaeology of Ritual, Religion, Status and Identity, pp. 101-113, Sharyn Jones O’Day, Win Van Neer y Anton Ervynck (eds.). Oxford: Oxbow Books.

2009 "Perspectives on Ancient Maya Bone Crafting from a Classic Period BoneArtifact Manufacturing Assemblage", Journal of Anthropological Archaeology, 28 (4): 458-470. Dol: https://doi.org/10.1016/j.jaa.2009.07.003.

Emery, Kitty F. y Kazuo Aoyama

2007 "Bone Tool Manufacturing in Elite Maya Households at Aguateca, Guatemala”, Ancient Mesoamerica, 18: 69-89.

Fridberg, Diana

2005 "Peccaries in Ancient Maya Economy, Ideology, and Iconography", tesis de licenciatura en Antropología. Massachusetts: Harvard University.

Garber, James F.

1989 Archaeology at Cerros, Belize, Central America, Volume II: The Artifacts. Dallas: Southern Methodist University Press.

Grube, Nicolai y Werner Nahm

1994 "A Census of Xibalba: A Complete Inventory of Way Characters on Maya Ceramics", The Maya Vase Book: A Corpus of Rollout Photographs of Maya Vases, pp. 686-715, Justin Kerr (ed.). New York: Kerr Associates.

Harding, Jan

2006 "Pit-Digging, Occupation, and Structured Deposition on Rudston Wold, Eastern Yorkshire”, Oxford Journal of Archaeology, 25 (2): 109-126. Dor: https:// doi.org/10.1111/j.1468-0092.2006.00252.x.

Jiménez Cano, Nayeli G.

2016 "Informe del estudio zooarqueológico de los restos faunísticos del Cuarto 4 del Palacio 6J2 de La Blanca (subops. 27 y 28)", Informe de las investigaciones arqueológicas del Proyecto La Blanca y su entorno, Petén, Guatemala (abril 2015mayo 2016). Informe inédito presentado al Ministerio de Educación, Cultura y Deporte de España y al Instituto de Antropología e Historia de Guatemala, Anexo 2, Cristina Vidal y Gaspar Muñoz (eds.). Valencia: Universidad de Valencia.

2017 "Informe zooarqueológico: la fauna del Cuarto 3 del ala sur de la Estructura $6 \mathrm{~J} 2$ de La Blanca (Petén, Guatemala)", Informe de las investigaciones arqueológicas del Proyecto La Blanca y su entorno, Petén, Guatemala (abril-mayo 2017). Informe inédito presentado a la Fundación Palarq y al Instituto de Antropología e Historia de Guatemala, Anexo 2, Cristina Vidal y Gaspar Muñoz (eds.). Valencia: Universidad de Valencia.

Koželsky, Kristin L.

2005 "Identifying Social Drama in the Maya Region: Fauna from the Lagartero 
Basurero, Chiapas, Mexico", tesis de maestría en Antropología. Tallahassee: Florida State University.

Laporte Molina, Juan Pedro

2004 "Terminal Classic Settlement and Polity in the Mopan Valley, Peten, Guatemala", The Terminal Classic in the Maya Lowlands, pp. 195-230, Arthur Demarest, Prudence Rice y Don Rice (eds.). Boulder: University Press of Colorado.

Lucero, Lisa J.

2006 Water and Ritual: The Rise and Fall of Classic Maya Rulers. Austin: University of Texas Press.

Montero López, Coral

2009 "Sacrifice and Feasting among the Classic Maya Elite, and the Importance of the White-Tailed Deer: Is there a Regional Pattern?", Journal of Historical and European Studies, 2: 53-68.

Morales Mejía, Fabiola, Joaquín Arroyo Cabrales y Óscar J. Polaco

2010 "Estudio comparativo de algunos elementos de las extremidades anteriores y posteriores y piezas dentales de puma (Puma concolor) y jaguar (Panthera onca)", Revista Especializada en Ciencias Químico-Biológicas, 13 (2): 73-90.

Muñoz Cosme, Gaspar y Cristina Vidal Lorenzo (eds.)

2006 La Blanca. Arquitectura y clasicismo. Valencia: Editorial de la Universitat Politècnica de València.

Muñoz Cosme, Gaspar y Cristina Vidal Lorenzo

2014 "La Blanca, un asentamiento urbano maya en la cuenca del río Mopán", LiminaR. Estudios Sociales y Humanísticos, XII (1): 36-52.

Nájera Coronado, Marta Ilia

2020 "El lenguaje ritual del fuego en los mayas del periodo Clásico: un acercamiento", Estudios de Cultura Maya, LIV: 91-127. Dol: https://dx.doi.org/10.19130/ iifl.ecm.2019.54.993.

Newman, Sarah

2013 "Animales como artefactos: el uso ritual de los restos de fauna por los antiguos mayas", XXVI Simposio de Investigaciones Arqueológicas en Guatemala 2012, pp. 587-596, Bárbara Arroyo y Luis Méndez Salinas (eds.). Guatemala: Museo Nacional de Arqueología y Etnología.

Olsen, Seymur

1968 Fish, Amphibian and Reptile Remains from Archaeological Sites. Cambridge: Harvard University Press (Papers of the Peabody Museum of Archaeology and Ethnology, 56).

1982 An Osteology of Some Maya Mammals. Cambridge: Harvard University Press (Papers of the Peabody Museum of Archaeology and Ethnology, 73). 
Peterson, Jeanette F.

1990 Precolumbian Flora and Fauna: Continuity of Plant and Animal Themes in Mesoamerica. La Jolla: Mingei International Museum of World Folk Art.

Pohl, Mary D.

1976 "Ethnozoology of the Maya", tesis de doctorado en Antropología. Cambridge: Harvard University.

1981 "Ritual Continuity and Transformation in Mesoamerica: Reconstructing the Ancient Maya Cuch Ritual”, American Antiquity, 46 (3): 513-529. DoI: https:// doi.org/10.2307/280598.

1983 "Maya Ritual Faunas: Vertebrate Remains from Burials, Caches, Caves, and Cenotes in the Maya Lowlands", Civilization in the Ancient Americas, pp. 55103, A. Kolata (ed.). Albuquerque: University of New Mexico Press.

Roys, Ralph L.

1965 "Lowland Maya Native Society at Spanish Contact", Archaeology of Southern Mesoamerica, Part Two, pp. 659-678, Gordon R. Willey (ed.), Robert Wauchope (ed. general). Austin: University of Texas Press (Handbook of Middle American Indians, 3).

Saunders, Nicholas J.

1994 "Tezcatlipoca: Jaguar Metaphors and the Aztec Mirror of Nature", Signifying Animals: Human Meaning in the Natural World, pp. 159-177, Roy Willis (ed.), One World Archaeology 16. London: Routledge.

Seler, Eduard

1996 "The Animal Pictures of the Mexican and Maya Manuscripts", Collected Works in Mesoamerican Linguistics and Archaeology, vol. 5, pp. 167-340. Culver City: Labyrinthos.

Sharpe, Ashley, Kitty Emery, Takeshi Inomata, Daniela Triadan, George Kamenov y John Krigbaum

2018 "Earliest Isotopic Evidence in the Maya Region for Animal Management and Long-Distance Trade at the Site of Ceibal, Guatemala", Proceedings of the National Academy of Sciences, 115 (14): 3605-3610. Dol: https://doi.org/10.1073/ pnas. 1713880115 .

Stanton, Travis W., Kathryn M. Brown y Jonathan B. Pagliaro

2008 "Garbage of the Gods? Squatters, Refuse Disposal, and Termination Rituals among the Ancient Maya”, Latin American Antiquity, 19 (3): 227-247. Dol: https://doi.org/10.1017/S1045663500007938.

Valdés Gómez, Juan Antonio y Cristina Vidal Lorenzo

2007 “Observaciones sobre el colapso y el periodo Clásico Terminal”, La Blanca y su entorno. Cuadernos de arquitectura y arqueología maya, pp. 173-179, Cristina Vidal y Gaspar Muñoz (eds.). Valencia: Editorial de la Universitat Politècnica de València. 
Varela Scherrer, Carlos Miguel

2017 "Análisis de los materiales arqueozoológicos", Excavaciones en el Templo XIX de Palenque, Chiapas, México, pp. 155-165, Alfonso Morales y Martha Cuevas (eds.). San Francisco: Precolumbia Mesoweb Press.

Vargas Garcíaguirre, Noris

2012 "Relaciones entre félidos y humanos en las tierras bajas mayas", tesis de licenciatura en Arqueología. Mérida: Universidad Autónoma de Yucatán.

Vidal Lorenzo, Cristina

2006 "La arqueología”, La Blanca. Arquitectura y clasicismo, pp. 12-26, Gaspar Muñoz y Cristina Vidal (eds.). Valencia: Editorial de la Universitat Politècnica de València.

Vidal Lorenzo, Cristina y Patricia Horcajada Campos

2020 "Water Rituals and Offerings to the Maya Rain Divinities", European Journal of Science and Theology, 16 (2): 111-123.

Vidal Lorenzo, Cristina y Gaspar Muñoz Cosme

2009 "Emigraciones y nuevos asentamientos en el Clásico Tardío. Una visión desde la arqueología y la arquitectura", Diásporas, migraciones y exilios en el mundo maya, pp. 133-149, Mario Ruz, Joan García Targa y Andrés Ciudad Ruiz (eds.). Mérida: Sociedad Española de Estudios Mayas, Universidad Nacional Autónoma de México, Centro Peninsular en Humanidades y Ciencias Sociales.

2013 "La crisis de La Blanca en el Clásico Terminal”, Millenary Maya Societies: Past Crises and Resilience, pp. 92-105, Charlotte Arnauld y Alain Breton (eds.). Paris: Mesoweb.

2016a "Chilonché y La Blanca. Arquitectura monumental en la cuenca del río Mopán”, Arqueología Mexicana, XXIII (137): 60-67.

2016b "Evidencias materiales de ritos funerarios tras el abandono: el caso de La Blanca, Petén”, Dimensions of Rituality 2000 Years Ago and Today, pp. 98-107, Christa Schieber y Miguel Orrego (eds.). Guatemala: Ministerio de Cultura y Deportes.

2017 "Investigaciones arqueológicas en la cuenca del río Mopán. El Proyecto La Blanca y su entorno", Mayas. El enigma de las ciudades perdidas, pp. 230-241, Juan Antonio López Padilla (ed.), catálogo de exposición. Alicante: Museo Arqueológico de Alicante.

Vidal Lorenzo, Cristina y Miguel Rivera Dorado

2017 Popol Vuh. Madrid: Alianza Editorial.

Vidal Lorenzo, Cristina y Juan A. Valdés Gómez

2007 "La huella arqueológica del abandono de los palacios de La Blanca", La Blanca y su entorno. Cuadernos de arquitectura y arqueología maya, pp. 11-20, Cristina Vidal y Gaspar Muñoz (eds.). Valencia: Editorial de la Universidad Politécnica de Valencia. 
Vogt, Evon Z.

1993 Tortillas for the Gods: A Symbolic Analysis of Zinacanteco Rituals. Norman: University of Oklahoma Press.

Nayeli G. Jiménez Cano. Mexicana. Licenciada en Arqueología por la Universidad Autónoma de Yucatán; maestra en Ciencias en Paleoecología Humana por la Universidad de Durham, y doctora en Biología por la Universidad Autónoma de Madrid. Se encuentra adscrita a la Facultad de Ciencias Antropológicas de la Universidad Autónoma de Yucatán. Sus especialidades son la zooarqueología maya y la arqueología ambiental, y desarrolla el proyecto "Cambios ambientales y adaptaciones sociales en las Tierras Bajas del Norte". Entre sus publicaciones recientes se encuentran "Pre-Hispanic Maya Fisheries and Coastal Adaptations in the Northern Lowlands from the Classic (500-900 AD) to Postclassic (900-1400 $\mathrm{AD})$ periods" y "Pesquerías de un asentamiento costero del Clásico Maya: análisis ictioarqueológicos en Xcambó (Yucatán, México)”, ambas en coautoría.

njimenezcano@gmail.com

Cristina Vidal Lorenzo. Española. Licenciada en Geografía e Historia y doctora en Geografía e Historia (especialidad en Antropología y Arqueología de América) por la Universidad Complutense de Madrid. Se desempeña como catedrática del Departamento de Historia del Arte en la Universidad de Valencia. Sus especialidades son el arte y la arqueología maya, y su proyecto en curso se titula "Arte y Arquitectura maya. Nuevas tecnologías para su estudio y conservación”. Entre sus publicaciones recientes pueden mencionarse "Water Rituals and Offerings to the Maya Rain Divinities", "El mural de Chilonché: estudio preliminar" y Popol $V u h$, todas en coautoría.

cristina.vidal@uv.es 